\title{
Human Platelet Antigens in Brazilian Multiethnic Populations: Occurrence of Regional Variation and Frequency in a Large Urban Center (Belo Horizonte)
}

\author{
Maria Clara Fernandes Silva-Malta ${ }^{a}$ Lucas Gabriel Tavares de Oliveira ${ }^{a}$ \\ Luísa Ferreira Barreiros $^{a}$ Dilson Rocha do Amaral ${ }^{b}$ Marina Lobato Martins ${ }^{a}$ \\ a Serviço de Pesquisa, Fundação Centro de Hematologia e Hemoterapia de Minas Gerais, Fundação Hemominas, Belo Horizonte, Brazil; \\ ${ }^{b}$ Setor de Aférese, Hemocentro de Belo Horizonte, Fundação Hemominas, Belo Horizonte, Brazil
}

\section{Keywords}

Platelets · Human platelet antigens · Real-time PCR . Genotyping

\section{Summary}

Background: The frequency of human platelet antigens (HPA) varies according to ethnicity, which causes differences in the morbidity of alloimmune and autoimmune thrombocytopenic disorders in different populations. Studies on HPA frequencies in Brazil have reported differences among Brazilian populations produced by the diverse degrees of admixture throughout the country. Methods: In the present study, we investigated the variation of HPA distribution in Brazil, compared with worldwide populations, and describe the frequencies of HPA$1,-2,-3,-5$, and -15 in a large urban center in Southern Brazil (Belo Horizonte) based on a sample of blood donors. Results: The principal component analysis and the dendrogram based on genetic distance revealed a clear relationship between Brazilian populations and the groups formed by European and African populations. The coefficients of variation for HPA allele frequencies suggest that Brazilian populations presented variations for HPA alleles comparable with the populations from continental groups. In Belo Horizonte, the allele a frequencies for HPA-1, $-2,-3,-5$ and -15 were $0.8575,0.8400$, $0.6225,0.8525$ and 0.5825 respectively. The genotypes with higher frequencies were a/a (72-74\%), except for HPA-3 and -15, whose heterozygous a/b genotypes were shown to be more prevalent $(43.5$ and $44.5 \%$, respectively). Conclusion: We confirmed the heterogeneity of HPA antigens in Brazilian populations, reinforcing the importance of HPA panels composed of regional blood donors, or a national panel that contemplates the specificities of the different regions of the country, in order to provide support in platelet transfusions and to minimize the risks associated with HPA alloimmunization. The evaluation of HPA data from Belo Horizonte represents the initial step toward the development of a genotyped platelet donor registry in order to treat HPA alloimmunized patients in this region.

(c) 2018 S. Karger GmbH, Freiburg

\section{Introduction}

Platelet transfusions are administered to prevent or treat bleeding in patients with quantitative or qualitative platelet disorders. However, human platelet antigens (HPA) can induce alloantibody production after HPA-incompatible transfusion in antigen-negative individuals or due to fetomaternal incompatibility for HPA [1]. Alloantibodies against HPA are implicated in alloimmune thrombocytopenic disorders (AIT), like post-transfusion purpura or neonatal alloimmune thrombocytopenia (NAIT), and in refractoriness to platelet transfusions [1-4].

To date, the Immuno Polymorphism Database lists 35 platelet alloantigens (www.ebi.ac.uk/ipd/hpa/). The frequency of these antigens varies according to ethnicity, which causes differences in the incidence of antigen specificity of anti-HPA antibodies and in the morbidity of AIT in different populations [5, 6]. In Europeans, alloantibodies are formed most commonly against HPA-1, -2, and -5. Antibodies against HPA-1a account for more than $80 \%$ of cases of NAIT in Africans and Europeans [4]. In contrast, alloimmunization to anti-HPA- $4 \mathrm{~b}$ is the predominant cause of NAIT in the Japanese population [7].

\section{KARGER}

(C) 2018 S. Karger GmbH, Freiburg 
Table 1. Populations included in the comparisons of HPA frequencies

\begin{tabular}{|c|c|c|}
\hline \multirow[t]{2}{*}{ Ancestry } & \multicolumn{2}{|l|}{ Worldwide populations } \\
\hline & populations from previous studies & populations from the 1000 Genomes Project Consortium [12] \\
\hline \multirow[t]{7}{*}{ African } & 4- Benin, Fon, Adja [13] & 30- African Caribbean in Barbados \\
\hline & 18- Cameroon, Bamileke, Duala, Beti [13] & 31- African Ancestry in Southwest US \\
\hline & 19- Central African Republic, Aka pygmies [13] & 32- Esan in Nigeria \\
\hline & 22- Congo, Bantu [13] & 33- Gambian in Western Division \\
\hline & & 34- Luhya in Webuye, Kenya \\
\hline & & 35- Mende in Sierra Leone \\
\hline & & 36- Yoruba in Ibadan, Nigeria \\
\hline \multirow[t]{4}{*}{ Amerindian } & 2- Argentinian Amerindian Toba [14] & 37- Colombian in Medelin, Colombia \\
\hline & 7- Brazil, Amazon Indians [10] & 38- Mexican Ancestry in Los Angeles \\
\hline & 10- Amazon Indians (Xikrin-Kayapo) [15] & 39- Peruvian in Lima, Peru \\
\hline & & 40- Puerto Rican in Puerto Rico \\
\hline \multirow[t]{5}{*}{ East Asia } & 20- China, Han [16] & 41- Chinese Dai in Xishuangbanna, China \\
\hline & 21- China, Han [17] & 42- Han Chinese in Bejing, China \\
\hline & 29- Vietnam, Kinh [18] & 43- Southern Han Chinese, China \\
\hline & 24-Ma'ohis_French Polinesia [18] & 44- Japanese in Tokyo, Japan \\
\hline & & 45- Kinh in HoChiMinh City, Vietnam \\
\hline \multirow[t]{7}{*}{ European } & 1- Argentinian Caucasian [14] & 46- Utah, Northern, and Western European Ancestry \\
\hline & 3- Austria/Styria, Caucasian [19] & 47- Finnish in Finland \\
\hline & 23- Czech Republic, Caucasian [20] & 48- British in England and Scotland \\
\hline & 25- Germany, Caucasians [21] & 49- Iberian populations in Spain \\
\hline & 26- Italy, Caucasian [22] & 50- Toscani in Italy \\
\hline & 27- Slovenian, Caucasian [23]) & \\
\hline & 28- Switzerland, Caucasian [24] & \\
\hline \multirow[t]{5}{*}{ South Asia } & & 51- Bengali in Bangladesh \\
\hline & & 52- Guraji Indian in Houston, TX \\
\hline & & 53- Indian Telugu in the UK \\
\hline & & 54- Punjabi in Lahone, Pakistan \\
\hline & & 55- Sri Lanka Tamil in the UK \\
\hline Ancestry & Brazilian populations & \\
\hline \multirow[t]{11}{*}{ Brazil } & 5- São Paulo - Caucasian [10] & \\
\hline & 6- Bahia - African-descents [10] & \\
\hline & 8- Paraná - blood donors [11] & \\
\hline & 9- Paraná - blood donors - Japanese descent [11] & \\
\hline & 11- São Paulo - blood donors [15] & \\
\hline & 12- Amazonas - blood donors [25] & \\
\hline & 13- Rio Grande do Sul - platelet donors - Caucasian [26] & \\
\hline & 14- Rio Grande do Sul - platelet donors - non Caucasian [26] & \\
\hline & 15- São Paulo - platelet donors [5] & \\
\hline & 16- São Paulo - patients with hematologic malignancies [27] & \\
\hline & 17- Minas Grais - platelet donors (present study) & \\
\hline
\end{tabular}

HPA determination is important for the diagnosis and treatment of patients with AIT syndromes. Platelet genotyping is considered the gold standard for HPA typing and is useful when correlated with the results of antibody testing to determine alloimmunization and to measure the risk of AIT [8].

The Brazilian population is very heterogeneous, being formed by extensive admixture between Amerindians, Africans, and Europeans [9]. Studies on HPA frequencies in Brazil have proposed the occurrence of heterogeneity across the Brazilian population produced by the different degrees of admixture throughout the coun- try, suggesting the importance of the formation of HPA panels composed of regional blood donors $[10,11]$.

In this study we present a broad comparison of HPA in worldwide populations, including data from Brazilian populations from different regions and with different ethnic backgrounds. Furthermore, we describe for the first time the frequencies of HPA-1, -2, $-3,-5$, and -15 in Belo Horizonte, a large urban center in Southern Brazil, based on a sample of blood donors. Belo Horizonte is the capital of the State of Minas Gerais, located in the southeast region of Brazil, and its metropolitan area $\left(9,460 \mathrm{~km}^{2}\right.$ and approximately 
5 million inhabitants) is ranked as the third most populous area in Brazil. The genotype data integrated a nascent database for searching for HPA-compatible donors in order to treat HPA-alloimmunized patients in this region.

These results provide an informative background of HPA polymorphisms in this highly admixed population and may be useful to support platelet transfusions, minimizing the risks associated with HPA alloimmunization.

\section{Material and Methods}

\section{Study Population}

In total, 200 volunteer platelet apheresis donors participated in the study. All individuals were male and unrelated to each other. The sample consisted exclusively of male donors because the Fundação Hemominas selects only men for apheresis platelet donations. This measure is taken to reduce the risk of TRALI since women are more likely to produce anti-HLA antibodies as a result of pregnancy. However, since it is expected that there is no difference in the frequency of HPA between men and women, we consider that this sample represents the general population. The donors were enrolled between March and May 2016 at Belo Horizonte blood center (Hemocentro de Belo Horizonte, Fundação Hemominas). The Fundação Hemominas is the main public blood center in Belo Horizonte. Written consent for the study was obtained from all individuals.

HPA frequency data from worldwide populations used for analysis and comparisons were obtained from the Immuno Polymorphism Database, EMBLEBI (www.ebi.ac.uk/ipd/hpa/index.html), the 1000 Genomes project (www.internationalgenome.org/) [12], or were derived from previous studies on HPA frequencies (tables 1,2). Only populations with results for at least HPA-1, 2, 3, and 5 and with data published in scientific studies were included in our analysis.

This study was approved by the Hemominas Ethical Committee (CAAE 43237615.7.0000.5118)

\section{HPA Genotyping}

Genomic DNA was extracted from the peripheral blood samples of platelet donors using the Biopur Kit (Mobius Life Science, Pinhais, Brazil), according to the manufacturer's instructions. Genotyping for HPA-1 (rs 5918), -2 (rs6065), -3 (rs5911), -5 (rs1801106), and -15 (rs10455097) used 1× TaqMan ${ }^{\mathrm{TM}}$ SNP genotyping assay (Applied Biosystems, Foster City, CA, USA), 1× TaqMan ${ }^{\mathrm{TM}}$ Genotyping Master Mix (Applied Biosystems), and 100 ng DNA. Each pre-designed TaqMan $^{\mathrm{TM}}$ SNP genotyping assay (C__818008_30, C__11442703_10, C_3017440_10, C_27862812_10 and C__3226894_10 for HPA-1, -2, -3, -5, and 15, respectively) contained VIC and FAM dye-labeled probes for the alleles $\mathrm{a}$ and $\mathrm{b}$ and two target-specific primers. HPA-1, $-2,-3,-5$, and 15 were selected among the more than 30 known HPA due to their relevance in transfusion medicine. All reactions were performed on a real-time PCR system model ABI 7500 Fast (Applied Biosystems) under the following conditions: a pre-amplifi-

Table 2. Human platelet antigens alleles and genotypes in Brazil compared to worldwide populations

\begin{tabular}{|c|c|c|c|c|c|c|c|}
\hline \multirow[t]{2}{*}{$\mathrm{N}$} & \multirow[t]{2}{*}{ Population } & \multicolumn{5}{|c|}{ HPA allele "a" frequencies } & \multirow[t]{2}{*}{ Reference } \\
\hline & & HPA-1 & HPA-2 & HPA-3 & HPA-5 & HPA-15 & \\
\hline 1 & Argentinian Caucasian & 0.878 & 0.875 & 0.612 & 0.927 & 0.511 & {$[14]$} \\
\hline 2 & Argentinian Amerindian Toba & 1.000 & 0.944 & 0.389 & 1.000 & 0.685 & {$[14]$} \\
\hline 3 & Austria/Styria, Caucasian & 0.830 & 0.870 & 0.620 & 0.920 & NA & {$[19]$} \\
\hline 4 & Benin, Fon, Adja & 0.896 & 0.708 & 0.679 & 0.818 & 0.646 & {$[13]$} \\
\hline 6 & Brazil, African-descents & 0.903 & 0.810 & 0.666 & 0.876 & NA & {$[10]$} \\
\hline 7 & Brazil, Amazon Indians & 1.000 & 0.821 & 0.757 & 1.000 & NA & {$[10]$} \\
\hline 8 & Brazil, mixed blood donors (Paraná) & 0.881 & 0.884 & 0.659 & 0.925 & 0.522 & {$[11]$} \\
\hline 9 & Brazil, Japanese descents (Paraná) & 0.978 & 0.893 & 0.579 & 0.975 & 0.553 & [11] \\
\hline 10 & Amazon Indians (Xikrin-Kayapo) & 1.000 & 0.963 & 0.708 & 0.963 & 0.780 & {$[15]$} \\
\hline 11 & Brazil, blood donors (São Paulo) & 0.918 & 0.816 & 0.640 & 0.825 & NA & {$[15]$} \\
\hline 13 & Brazil, blood donors (Porto Alegre), Caucasian & 0.867 & 0.895 & 0.621 & 0.903 & 0.500 & {$[26]$} \\
\hline 14 & Brazil, blood donors (Porto Alegre), non-Caucasian & 0.794 & 0.868 & 0.662 & 0.809 & 0.471 & {$[26]$} \\
\hline 15 & Brazil, blood donors (São Paulo) & 0.853 & 0.878 & 0.649 & 0.902 & 0.533 & {$[5]$} \\
\hline 16 & Patients with hematologic malignancies (São Paulo) & 0.837 & 0.830 & 0.700 & 0.887 & 0.457 & {$[27]$} \\
\hline 17 & Brazilian blood donors (Belo Horizonte) & 0.858 & 0.840 & 0.623 & 0.853 & 0.583 & present study \\
\hline 18 & Cameroon, Bamileke, Duala, Beti & 0.907 & 0.763 & 0.614 & 0.746 & 0.691 & [13] \\
\hline 19 & Central African Republic, Aka pygmies & 1.000 & 0.607 & 0.5 & 0.595 & 0.698 & [13] \\
\hline 20 & China, Han & 0.994 & 0.952 & 0.5945 & 0.986 & 0.532 & {$[16]$} \\
\hline 21 & China, Han & 1.000 & 0.955 & 0.588 & 0.977 & 0.582 & {$[17]$} \\
\hline 22 & Congo, Bantu & 0.904 & 0.776 & 0.596 & 0.732 & 0.701 & [13] \\
\hline 23 & Czech Republic, Caucasian & 0.830 & 0.90 & 0.59 & 0.93 & NA & {$[20]$} \\
\hline 24 & Ma'ohis_Frensh Polinesia & 0.975 & 0.913 & 0.599 & 0.975 & 0.463 & {$[18]$} \\
\hline 25 & Germany, Caucasians & 0.839 & 0.910 & 0.586 & 0.917 & NA & {$[21]$} \\
\hline 26 & Italy, Caucasian & 0.850 & 0.89 & 0.61 & 0.9 & NA & {$[22]$} \\
\hline 29 & Vietnam, Kinh & 0.986 & 0.953 & 0.486 & 0.972 & 0.477 & [H18] \\
\hline
\end{tabular}


Table 2. Continued

\begin{tabular}{|c|c|c|c|c|c|c|c|}
\hline \multirow[t]{2}{*}{$\mathrm{N}$} & \multirow[t]{2}{*}{ Population } & \multicolumn{5}{|c|}{ HPA allele "a" frequencies } & \multirow[t]{2}{*}{ Reference } \\
\hline & & HPA-1 & HPA-2 & HPA-3 & HPA-5 & HPA-15 & \\
\hline 30 & ACB: African Caribbean in barbados & 0.891 & 0.755 & 0.562 & 0.797 & 0.365 & \multirow{26}{*}{$\begin{array}{l}\text { The } 1000 \\
\text { Genomes } \\
\text { Project } \\
\text { Consortium }\end{array}$} \\
\hline 31 & ASW: African Ancestry in Southwest US & 0.918 & 0.754 & 0.574 & 0.803 & 0.377 & \\
\hline 32 & ESN: Esan in Nigeria & 0.909 & 0.793 & 0.646 & 0.783 & 0.359 & \\
\hline 33 & GWD: Gambian in Western Division & 0.929 & 0.774 & 0.527 & 0.898 & 0.358 & \\
\hline 34 & LWK: Luhya in Webuye, Kenya & 0.884 & 0.692 & 0.606 & 0.636 & 0.318 & \\
\hline 35 & MSL: Mende in Sierra Leone & 0.982 & 0.712 & 0.494 & 0.841 & 0.341 & \\
\hline 36 & YRI: Yoruba in Ibadan, Nigeria & 0.861 & 0.755 & 0.556 & 0.810 & 0.310 & \\
\hline 37 & CLM: Colombian in Medelin, Colombia & 0.894 & 0.856 & 0.644 & 0.920 & 0.548 & \\
\hline 38 & MXL: Mexican Ancestry in Los Angeles, CA & 0.898 & 0.867 & 0.570 & 0.961 & 0.367 & \\
\hline 39 & PEL: Peruvian in Lima, Peru & 0.947 & 0.818 & 0.594 & 0.959 & 0.524 & \\
\hline 40 & PUR: Puerto Rican in Puerto Rico & 0.861 & 0.846 & 0.702 & 0.909 & 0.495 & \\
\hline 41 & CDX: Chinese Dai in Xishuangbanna, China & 1.000 & 0.935 & 0.484 & 0.957 & 0.452 & \\
\hline 42 & CHB: Han Chinese in Bejing, China & 0.990 & 0.937 & 0.544 & 0.981 & 0.495 & \\
\hline 43 & CHS: Southern Han Chinese, China & 0.995 & 0.967 & 0.576 & 0.971 & 0.429 & \\
\hline 44 & JPT: Japanese in Tokyo, Japan & 0.990 & 0.856 & 0.601 & 0.947 & 0.538 & \\
\hline 45 & KHV: Kinh in HoChiMinh City, Vietnam & 0.980 & 0.955 & 0.505 & 0.985 & 0.449 & \\
\hline 46 & CEU: Utah, Northern and Western European Ancestry & 0.874 & 0.944 & 0.626 & 0.899 & 0.429 & \\
\hline 47 & FIN: Finnish in Finland & 0.889 & 0.864 & 0.571 & 0.924 & 0.646 & \\
\hline 48 & GBR: British in England and Scotland & 0.868 & 0.934 & 0.621 & 0.934 & 0.478 & \\
\hline 49 & IBS: Iberian populations in Spain & 0.864 & 0.907 & 0.603 & 0.893 & 0.467 & \\
\hline 50 & TSI: Toscani in Italy & 0.846 & 0.916 & 0.636 & 0.911 & 0.505 & \\
\hline 51 & BEB: Bengali in Bangladesh & 0.890 & 0.930 & 0.628 & 0.901 & 0.651 & \\
\hline 52 & GIH: Guraji Indian in Houston, TX & 0.908 & 0.932 & 0.660 & 0.922 & 0.680 & \\
\hline 53 & ITU: Indian Telugu in the UK & 0.877 & 0.936 & 0.672 & 0.907 & 0.686 & \\
\hline 54 & PJL: Punjabi in Lahone, Pakistan & 0.870 & 0.932 & 0.656 & 0.932 & 0.615 & \\
\hline 55 & STU: Sri Lanka Tamil in the UK & 0.887 & 0.956 & 0.701 & 0.897 & 0.652 & \\
\hline
\end{tabular}

cation step of $60^{\circ} \mathrm{C}$ for $30 \mathrm{~min}$ and $95^{\circ} \mathrm{C}$ for $10 \mathrm{~min}$, followed by 40 cycles at $95^{\circ} \mathrm{C}$ for $15 \mathrm{~s}$ and $64^{\circ} \mathrm{C}$ for $1 \mathrm{~min}$, and a post-amplification step of $60^{\circ} \mathrm{C}$ for 30 s. We successfully constructed positive controls for use in the reactions, containing the specific SNP of each allele in four different fragment sequences (gBlocks ${ }^{\mathrm{TM}}$ Gene Fragments; Integrated DNA Technologies, Skokie, IL, USA): HPA-1a-2a; HPA-1b-2b, HPA-3a-5a-15b, and HPA-3b-5b-15a. The analysis was performed using the Allelic Discrimination Plot.

\section{Statistical Analysis}

The HPA genotype and allele frequencies were compared according to ABO and Rh blood group systems by chi square or Fisher's exact test using the GraphPad Prism 5 software package (GraphPad Software, San Diego, CA, USA). Tests of Hardy-Weinberg equilibrium were performed for each HPA comparing expected and observed genotype frequencies by Fisher's exact test. Differences were considered significant when $\mathrm{p}$ values were $<0.05$.

Principal component analysis (PCA) based on the HPA-1, $-2,-3,-5$, and -15 allele frequencies was performed by using the ClustVis web tool [28] to analyze the relationship between Belo Horizonte blood donors, individuals from other Brazilian regions, and the worldwide populations. Table 1 shows the populations used in this analysis.

Genetic distances based on the HPA alleles were used to construct a dendrogram using the neighbor-joining method implemented in the PHYLIP software package $[29,30]$ to summarize the affinities between the Brazilian and other populations. The tree was drawn with the FIGTREE program (http://tree.bio. ed.ac.uk/software/figtree/). The worldwide populations used in this analysis belong to 1000 Genomes projects, and the Brazilian populations were derived from previous studies, with the exception of Belo Horizonte (table 1). Populations from the 1000 Genomes project were selected because this dataset provides a reliable source of information about human genetic variation generated based on whole genome sequencing data from more than 2,500 individuals across 26 populations from five continental groups [12].

The coefficient of variation (CV) of HPA allele a frequencies was calculated as the ratio of the standard deviation to the mean for the five continental population groups characterized as part of the 1000 Genomes Project and for the Brazilian populations.

Comparisons of HPA allele count between different Brazilian groups were assessed by the chi square test using the OpenEpi tool (www.openepi.com/RbyC/ RbyC.htm). A p value $<0.05$ was considered a statistically significant difference.

\section{Results}

HPA genotyping was performed in 200 male platelet apheresis donors with mean blood donations of 21 (range 2-139) and a mean age of 38 years(rang 19-61 years). Their allele and genotype frequencies are shown in table 3 . The allele frequencies of all analyzed HPA systems were in Hardy-Weinberg equilibrium ( $p>0.05)$. The genotypes with higher frequencies were a/a (72-74\%), except for HPA-3 and -15 , whose heterozygous a/b genotypes were shown to be more prevalent ( $43.5 \%$ and $44.5 \%$, respectively). The most common genotype was HPA-1a/a (74\%), followed by HPA-5a/a $(72.5 \%)$ and HPA-2a/a (72\%), whereas the most uncommon was HPA-5b/b (2\%), followed by HPA-1b/b (2.5\%).

We also analyzed the frequency of HPA genotyping according to $\mathrm{ABO}$ and $\mathrm{Rh}$ blood systems. The most frequent blood group in 
Table 3. HPA allele and genotype frequencies in blood donors from Belo Horizonte, Brazil

\begin{tabular}{|c|c|c|c|c|c|}
\hline \multirow[t]{2}{*}{ Gene } & \multicolumn{2}{|l|}{ Allele } & \multicolumn{3}{|l|}{ Genotype } \\
\hline & $\mathrm{a}$ & $\mathrm{b}$ & $a / a$ & $\mathrm{a} / \mathrm{b}$ & $\mathrm{b} / \mathrm{b}$ \\
\hline HPA-1 & 0.8575 & 0.1425 & $148(0.740)$ & $47(0.235)$ & $5(0.250)$ \\
\hline HPA-2 & 0.8400 & 0.1600 & $144(0.720)$ & $48(0.240)$ & $8(0.040)$ \\
\hline HPA-3 & 0.6225 & 0.3775 & $81(0.405)$ & $87(0.435)$ & $32(0.160)$ \\
\hline HPA-5 & 0.8525 & 0.1475 & $145(0.725)$ & $51(0.255)$ & $4(0.020)$ \\
\hline HPA-15 & 0.5825 & 0.4175 & $72(0.360)$ & $89(0.445)$ & $39(0.195)$ \\
\hline
\end{tabular}

\begin{tabular}{|c|c|c|c|c|c|c|}
\hline \multirow[t]{2}{*}{ HPA genotype } & \multicolumn{6}{|c|}{$\mathrm{ABO} / \mathrm{RhD}$ blood group } \\
\hline & $\mathrm{O} / \mathrm{RhD}+$ & $\mathrm{A} / \mathrm{RhD}+$ & $\mathrm{B} / \mathrm{RhD}+$ & $\mathrm{AB} / \mathrm{RhD}+$ & $\mathrm{O} / \mathrm{RhD}_{-}$ & $\mathrm{B} / \mathrm{RhD}-$ \\
\hline \multicolumn{7}{|l|}{ HPA-1 } \\
\hline aa & $77(73.33 \%)$ & 44 (69.84\%) & $10(71.43 \%)$ & $5(100 \%)$ & $12(100 \%)$ & 0 \\
\hline $\mathrm{ab}$ & $25(23.81 \%)$ & $18(28.57 \%)$ & $3(21.43 \%)$ & 0 & 0 & $1(100 \%)$ \\
\hline $\mathrm{bb}$ & $3(2.86 \%)$ & $1(1.59 \%)$ & $1(7.14 \%)$ & 0 & 0 & 0 \\
\hline \multicolumn{7}{|l|}{ HPA-2 } \\
\hline aa & 79 (75.24\%) & $42(66.67 \%)$ & 10 (71.43\%) & $2(40.00 \%)$ & $10(83.33 \%)$ & $1(100 \%)$ \\
\hline $\mathrm{ab}$ & $22(20.95 \%)$ & $17(26.98 \%)$ & $4(28.57 \%)$ & $3(60.00 \%)$ & $2(16.67 \%)$ & 0 \\
\hline $\mathrm{bb}$ & $4(3.81 \%)$ & $4(6.35 \%)$ & 0 & 0 & 0 & 0 \\
\hline \multicolumn{7}{|l|}{ HPA-3 } \\
\hline aа & $42(40.00 \%)$ & $24(38.09 \%)$ & $6(42.86 \%)$ & $2(40.00 \%)$ & $6(50.00 \%)$ & $1(100 \%)$ \\
\hline $\mathrm{ab}$ & $46(43.81 \%)$ & $27(42.86 \%)$ & $7(50.00 \%)$ & $2(40.00 \%)$ & $5(41.67 \%)$ & 0 \\
\hline $\mathrm{bb}$ & $17(16.19 \%)$ & $12(19.05 \%)$ & $1(7.14 \%)$ & $1(20.00 \%)$ & $1(8.33 \%)$ & 0 \\
\hline \multicolumn{7}{|l|}{ HPA-5 } \\
\hline aa & 75 (71.43\%) & $46(73.02 \%)$ & $11(78.57 \%)$ & $4(80.00 \%)$ & $9(75.00 \%)$ & 0 \\
\hline $\mathrm{ab}$ & $26(24.76 \%)$ & $17(26.98 \%)$ & $3(21.43 \%)$ & $1(20.00 \%)$ & $3(25.00 \%)$ & $1(100 \%)$ \\
\hline $\mathrm{bb}$ & $4(3.81 \%)$ & 0 & 0 & 0 & 0 & 0 \\
\hline \multicolumn{7}{|l|}{ HPA-15 } \\
\hline aа & $35(33.33 \%)$ & $25(39.68 \%)$ & $6(42.86 \%)$ & $2(40.00 \%)$ & $3(25.00 \%)$ & $1(100 \%)$ \\
\hline $\mathrm{ab}$ & $54(51.43 \%)$ & $20(31.75 \%)$ & $5(35.71 \%)$ & $2(40.00 \%)$ & $8(66.67 \%)$ & 0 \\
\hline $\mathrm{bb}$ & $16(15.24 \%)$ & $18(28.57 \%)$ & $3(21.43 \%)$ & $1(20.00 \%)$ & $1(8.33 \%)$ & 0 \\
\hline
\end{tabular}

Table 4. HPA genotypes according $A B O$ and Rh blood groups the randomly enrolled donors was $\mathrm{O}+(52.5 \%)$ followed by $\mathrm{A}+$ $(31.5 \%)$ (table 4$)$. Comparing these two larger groups, the HPA genotype frequency was not significantly different, except for HPA-15 (chi square, $\mathrm{p}=0.025$ ), whose $\mathrm{A}+$ blood donors had a smaller proportion (31.75\%) of heterozygous than $\mathrm{O}+$ individuals $(51.43 \%)$. On the other hand, the allelic frequency was not significantly different between $\mathrm{A}+$ and $\mathrm{O}+$ individuals for any of the HPA alleles.

We identified 67 different HPA combinations, 31 of which occurred in only one individual, evidencing the diversity of allelic combinations. The most frequent was HPA-1aa/-2aa/-3ab/-5aa/ -15ab (17/200, 8.5\%). 20 (10\%) donors were homozygous a/a for HPA-1, -2, $-3,-5$, and heterozygous $\mathrm{a} / \mathrm{b}(\mathrm{n}=13)$ or homozygous $\mathrm{b} / \mathrm{b}(\mathrm{n}=7)$ for HPA-15. In addition, 13 (6.5\%) platelet donors were b-negative (homozygous a/a) for all HPA analyzed. As expected, individuals simultaneously heterozygous $\mathrm{a} / \mathrm{b}$ or homozygous $\mathrm{b} / \mathrm{b}$ for all HPA were not found. We also identified 13 individuals carrying rare allele combinations: HPA-3bb/15bb (3.5\%), HPA2bb/15bb (2.5\%), and HPA-3bb/5bb (0.5\%). Other combinations of homozygous b/b were not found. Four (2\%) donors (O+: 2; A+: $1 ; \mathrm{B}+: 1$ ) had the genotypic pattern HPA-1a/5b-negative (HPA$1 \mathrm{bb} / 5 \mathrm{aa})$, which is the most compatible profile to treat neonatal alloimmune thrombocytopenia.

A PCA was performed (fig. 1) based on the HPA-1, -2, -3, -5, and -15 allele frequencies using the ClustVis web tool and considering the populations listed in table 1 . To facilitate the analysis, we labeled the populations as follows: African, European, East Asia, South Asia, and Amerindian according to the geographic or ethnic origin (when the original study described the population as belonging to a particular ethnic group). Brazilian populations were labeled 'Brazil,' with the exception of Native American populations, which were labeled 'Amerindians.' PCA showed that the first two principal components accounted for $69.1 \%$ of the variability (39\% along axis 1 and $30.1 \%$ along axis 2), and revealed a clear relationship between diversity pattern of HPA and geographical/ethnic origin (fig. 1). In this analysis, the Brazilian populations were distributed heterogeneously, mainly between the groups formed by European and African populations. 
Fig. 1. PCA based on the gene frequencies of HPA-1, -2, -3, -5, and - 15 showing the relationships among different Brazilian and worldwide populations. The populations are described in table 1.
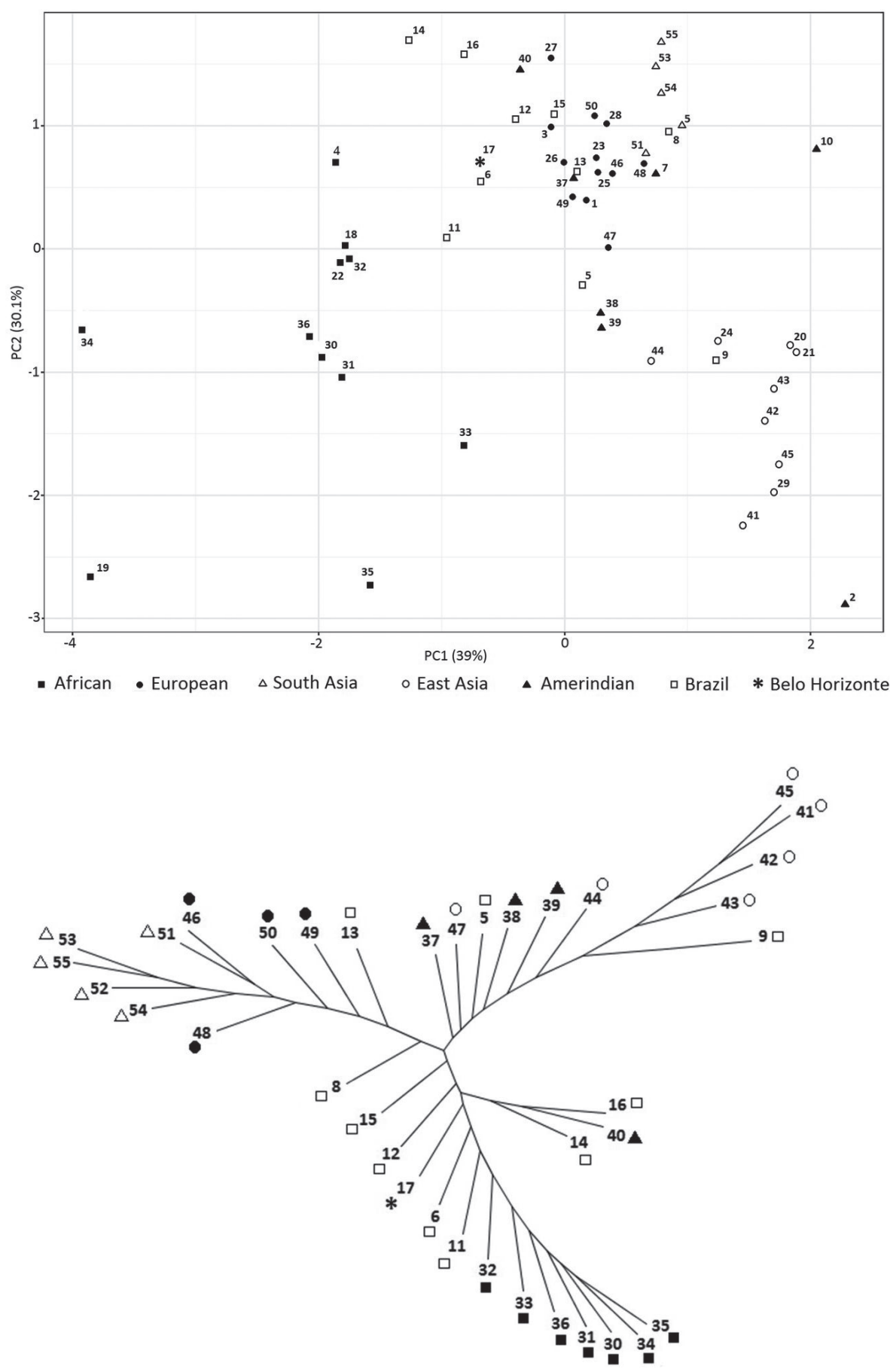

- African - European $\triangle$ South Asia OEast Asia $\Delta$ Amerindian $\quad$ Brazil $*$ Belo Horizonte
Fig. 2. Dendrogram based on HPA-1, $-2,-3$, and -5 frequencies showing the genetic relationships among Brazilians and other worldwide populations. The populations are presented in table 1 .
To evaluate the variation in HPA allelic frequencies in Brazil in comparison with other groups, we calculated the CV of HPA allele a frequencies for the Brazilian populations and for the populations that integrated each of the five continental groups from the 1000 Genomes Project. In the case of Brazilian populations, the CV was calculated considering all populations that originated from Brazil (populations 5 to 17 , table 1), and considering exclusively the predominantly admixed populations characteristic of the different
Brazilian regions (populations 8, 11, 12, 15, 16, and 17, table 1). The CV calculated for populations from continental groups ranged from 0.01 to 0.04 for HPA-1, 0.01 to 0.05 for HPA-2, 0.04 to 0.09 for HPA-3, 0.02 to 0.10 for HPA-5, and 0.04 to 0.17 for HPA-15 (table 5). In general, the CVs of Brazilian populations were within the range of CVs observed for the world's populations.

Comparison of HPA alleles between Brazilian populations was assessed by a global chi square test. Statistically significant differ- 
ences were observed for allele distributions of HPA-1, -2, -3, -5, and 15 when all Brazilian populations were considered ( $\mathrm{p}<0.01)$. However, when only predominantly admixed Brazilian groups were included in this analysis, a significant difference was observed only for HPA-5 and -15 ( $\mathrm{p}=0.004$ and 0.019 , respectively).

The heterogeneity in the HPA allelic frequency observed among distinct Brazilian populations, as reported in previous studies, was confirmed and expanded by these analyses, with the simultaneous inclusion of populations living in almost all Brazilian geographic regions: north, northeast, south, and southeast. Only the centerwest region was not included due to the absence of data.

A dendrogram was constructed using a genetic distance matrix combining HPA-1, $-2,-3$, and, -5 loci (fig. 2). In this dendrogram, only data from Brazil or the 1000 Genomes project were included in order to provide a more clear and informative tree. HPA 15 was not included in this analysis due to the large number of missing data for Brazilian populations. In this dendrogram, the majority of Brazilian admixed populations, including blood donors from Belo Horizonte, were included in a branch that contained African populations.

\section{Discussion}

Several studies have reported the distributions of HPA polymorphisms in worldwide populations, showing the existence of great variation among different ethnic and geographic groups. The Brazilian population is highly heterogeneous and admixed, presenting important differences in genomic ancestry among regions $[9,31]$. Studies carried out in Brazilian populations have demonstrated the existence of significant differences in the distribution of HPA antigens throughout the Brazilian territory [10, 25], which could generate regional differences in the risk of HPA alloimmunization and its consequences. In the present study, we investigated the variation of HPA frequencies in different Brazilian populations, compared with other world populations.

PCAs, performed with the HPA-1, -2, -3, -5, and -15 allele frequencies showed that, worldwide, populations from the same ethnic or geographic region tended to group together, revealing, as expected, affinity for the platelet antigen profile. Only the populations labeled as Amerindians (populations 2, 7, 10, 37, 38, 39, and 40) did not form a reasonably well-defined cluster. This result can be explained by the existence of marked differences in the frequency of platelet antigens among Amerindian populations, which have been attributed to the enormous amounts of genetic drift present in many South American native groups that has generated exceptional allele frequency variation [32, 33].

In PCA, Brazilian populations were distributed heterogeneously among European and African populations. This pattern is in agreement with historical records of the Brazilian colonization, corroborated by genetic studies. The Brazilian population originated from three main ancestral contributions: African, European, and Native American. However, their genetic ancestry varies greatly among the different Brazilian regions, with the largest African ancestry in northeastern areas, predominant European ancestry in the south-
Table 5. Coefficient of variation for HPA allele frequencies in different populations

\begin{tabular}{llllll}
\hline Population* & \multicolumn{5}{c}{ Coefficient of variation for HPA allele 'a' frequencies } \\
\cline { 2 - 6 } & HPA-1 & HPA-2 & HPA-3 & HPA-5 & HPA-15 \\
\hline African & 0.04 & 0.05 & 0.09 & 0.10 & 0.07 \\
Native American & 0.04 & 0.02 & 0.09 & 0.03 & 0.17 \\
East Asia & 0.01 & 0.05 & 0.09 & 0.02 & 0.09 \\
European & 0.02 & 0.03 & 0.04 & 0.02 & 0.17 \\
South Asia & 0.02 & 0.01 & 0.04 & 0.02 & 0.04 \\
Brazil (all) & 0.07 & 0.05 & 0.07 & 0.06 & 0.18 \\
Brazil (admixed) & 0.03 & 0.03 & 0.04 & 0.04 & 0.09 \\
\hline
\end{tabular}

*Worldwide populations belong to 1000 Genomes projects; Brazilian populations were derived from previous published studies.

\#Brazil (all): populations originated from Brazil including native American populations and groups artificially selected based on ethnic characteristics (populations 5 to 17 in table 1 ).

${ }^{\S}$ Brazil (admixed) admixed populations from different Brazilian regions (populations $8,11,12,15,16$ and 17 in table 1 ).

eastern and southern areas, and a larger influence of the Amerindian root in northern Brazil. Additionally, a great variation in individual admixture has been observed in Brazil [9, 31]. Blood donors from Belo Horizonte were consistently grouped with other Brazilian populations, reflecting the ancestry observed in blood donors from Minas Gerais, previously estimated as 33.8\% African, 57.7\% European, and 3.5\% Amerindian [34].

The PCA (fig. 1) and the dendrogram constructed using a genetic distance matrix combining HPA loci (fig. 2) also revealed a very close relationship between some Brazilian groups and worldwide populations, such as population 13 [26] and the European populations, and population 9 [11] and East Asian populations. However, it is important to note that these are not natural populations but rather groups of individuals selected by ethnic-racial criteria and described as 'Caucasians' (population 13) or 'Japanese descendants' (population 9).

To analyze the heterogeneity of HPA distribution in Brazil, we compared the CVs for HPA allele frequencies for populations from the five continental groups that were part of the 1000 Genomes Project and for Brazilian populations. The comparison indicates that, in general, Brazilian populations presented variation for HPA alleles comparable to the populations from continental groups. This occurred even when only admixed Brazilian populations were considered, although, in this case, the CVs were smaller (table 5). These results suggest that the frequencies of HPA observed in the different Brazilian populations may be as variable as those observed between the different countries of a continent. On the other hand, attention must be paid to the inclusion of artificially selected groups based on ethnic characteristics in this analysis to avoid overestimating the heterogeneity of HPA distribution. This observation was corroborated by the global chi square test performed for the distribution of HPA alleles in Brazilian populations.

The development of a panel of HPA-genotyped donors is important to enable the matched platelet selection for transfusions 
[35]. In a multiethnic country like Brazil, characterized by marked regional differences throughout the territory, it is important to study different populations regarding the distribution of platelet antigens to access regional differences and to detect the need for the establishment of panels composed of regional blood donors.

In countries with multi-ethnic and admixed populations, the risk of HPA alloimmunization may be higher than that observed in more homogeneous populations [36, 37]. This may occur due to a greater mismatch probability caused by the chance of ethnic differences between donors/patient (increasing the risk of alloimmunization by transfusion) and mothers/fathers (increasing the risk of NAIT). This information indicates the need of further studies on the incidence of NAIT and other alloimmune thrombocytopenic disorders in populations of South America, where these conditions seems to be underestimated [38].

This is the first report on the HPA allele frequencies in Belo Horizonte and represents the initial step toward the development of a genotyped platelet donor registry in order to treat HPA-alloimmunized patients in this region. We found a frequency of 0.1425 for the allele HPA-1b in Belo Horizonte (table 3). Considering that the blood donors represent the general population reasonably well and assuming that the population is in Hardy-Weinberg equilibrium, the frequency of HPA-1a-negative individuals is estimated to be $2.03 \%$. This relatively high frequency of HPA-1a-negative individuals highlight the risk of NAIT in this region, since antibodies against HPA-1a account for more than $80 \%$ of cases of this clinical condition in Africans and Europeans [4]. At the same time, HPA1a/5b-negative platelet donors were identified (2\%) and are poten- tial compatible donors of platelets for the treatment of NAIT, since transfusion with platelet concentrates with this haplotype are effective in the treatment of over $95 \%$ of cases of NAIT caused by maternal HPA antibodies $[39,40]$.

Considering that several donor characteristics, in addition to HPA frequencies, are relevant for the establishment of panels effective in meeting the transfusion needs [41] and that the incidence of alloimmune thrombocytopenic disorders in our populations is unknown, future studies to estimate the number of genotyped donors necessary to establish an appropriate platelet donor panel in Belo Horizonte are important.

In conclusion, we confirmed the heterogeneity of HPA antigens in Brazilian populations, reinforcing the importance of HPA panels composed of regional blood donors, or a national panel that contemplates the specificities of the different regions of the country, in order to provide support in platelet transfusions and minimize the risks associated with HPA alloimmunization.

\section{Acknowledgments}

The authors would like to thank all the participants in the study. This work was supported by grants from FAPEMIG (APQ-00657-15, RED-00314-16, and BIPDT fellowship) and Fundação Hemominas. MCSF, MLM, LGTO, and LFB received fellowships from FAPEMIG.

\section{Disclosure Statement}

The authors report no declarations of interest.

\section{References}

1 Curtis BR, McFarland JG: Human platelet antigens (2013). Vox Sang 2014;106:93-102.

2 Mueller-Eckhardt C, Kiefel V, Santoso S: Review and update of platelet alloantigen systems. Transfus Med Rev 1990;4:98-109.

3 Pappalardo PA, Secord AR, Quitevis P, Haimowitz $\mathrm{MD}$, Goldfinger D: Platelet transfusion refractoriness associated with HPA-1a (Pl(A1)) alloantibody without coexistent HLA antibodies successfully treated with antigen-negative platelet transfusions. Transfusion 2001;41:984-987.

4 Davoren A, Curtis BR, Aster RH, McFarland JG Human platelet antigen-specific alloantibodies implicated in 1162 cases of neonatal alloimmune thrombocytopenia. Transfusion 2004;44:1220-1225.

5 Conti F, Bertrand G, Dezan M, Costa T, Aravechia M, Mota M, Castilho L, Kaplan C, Kutner J: Molecular HPA genotyping by microarray in Brazilian blood donors. Transfusion 2014;54:405-411.

6 Chen L, Liu Z, Liu T, Ma X, Rao M, Wang Y, Sun B, Yin W, Zhang J, Yan B, Li X, Wang Q, Zhang L, Wen J, Liu F, Wang P, Wei Y, Huang Y, Wu J, Guo Y, Kang Y, Song X, Liu X, Zhang G, Xie T, Chen Y, Zeng X: Neonatal alloimmune thrombocytopenia caused by antiHPA antibodies in pregnant Chinese women: a study protocol for a multicentre, prospective cohort trial. BMC Pregnancy and Childbirth 2017;17:281.

7 Ohto H, Miura S, Ariga H, Ishii T, Fujimori K, Morita S; Collaborative Study Group: The natural history of maternal immunization against foetal platelet alloantigens. Transfus Med 2004;14:399-408.
8 Arinsburg SA, Shaz BH, Westhoff C, Cushing MM: Determination of human platelet antigen typing by molecular methods: importance in diagnosis and early treatment of neonatal alloimmune thrombocytopenia. Am J Hematol 2012;87:525-528.

9 Kehdy FS, Gouveia MH, Machado M, Magalhães WC, Horimoto AR, Horta BL, Moreira RG, Leal TP, Scliar MO, Soares-Souza GB, Rodrigues-Soares F, Araújo GS, Zamudio R, Sant Anna HP, Santos HC, Duarte NE, Fiaccone RL, Figueiredo CA, Silva TM, Costa GN, Beleza S, Berg DE, Cabrera L, Debortoli G, Duarte D, Ghirotto S, Gilman RH, Gonçalves VF, Marrero AR, Muniz YC, Weissensteiner H, Yeager M, Rodrigues LC, Barreto ML, Lima-Costa MF, Pereira AC, Rodrigues MR, Tarazona-Santos E; Brazilian EPIGEN Project Consortium: Origin and dynamics of admixture in Brazilians and its effect on the pattern of deleterious mutations. Proc Natl Acad Sci U S A 2015;112:8696-8701.

10 Castro V, Origa AF, Annichino-Bizzacchi JM, Soares M, Menezes RC, Goncalves MS, Costa FF, Arruda VR: Frequencies of platelet-specific alloantigen systems 1-5 in three distinct ethnic groups in Brazil. Eur J Immunogenet 1999;26:355-360.

11 Silvestre APA, Zacarias JMV, Guelsin GAS, Visentainer JEL, Sell AM: Genetic polymorphisms of human platelet antigens in Euro-African and Japanese descendants from Parana, Southern Brazil. Platelets 2017; 28:607-610.

12 The 1000 Genomes Project Consortium: A global reference for human genetic variation. Nature 2015;526: $68-74$.
3 Halle L, Bigot A, Mulen-Imandy G, M’Bayo K, Jaeger G, Anani L, Martageix C, Bianchi F, Julien E, Kaplan C: HPA polymorphism in sub-Saharan African populations: Beninese, Cameroonians, Congolese, and Pygmies. Tissue Antigens 2005;65:295-298.

14 De La Vega ECD, Nogués N, Fernández Montoya A, Chialina S, Blanzaco PD, Theiller E, Raillon MA, Arancegui N, Solis E, Oyonarte S, Crespo Ferrer V, Campos Muñoz A, Muñiz-Díaz E: Human plateletspecific antigens frequencies in the Argentinean population. Transfus Med 2008;18:83-90.

15 Chiba AK, Bordin JO, Kuwano ST, Figueiredo MS, Carvalho K, Vieira-Filho JPB, Kerbauy J: Platelet alloantigen frequencies in Amazon Indians and Brazilian blood donors. Transfus Med 2000;10:207-212.

16 Feng ML, Liu DZ, Shen W, Wang JL, Guo ZH, Zhang X, Du KM, Qian KC, Zhao TM: Establishment of an HPA-1- to -16-typed platelet donor registry in China. Transfus Med 2006;16:369-374.

17 Xu X, Zhu F, Ying Y, Tao S, Liu Y, Hong X, Yan L: Simultaneous genotyping of human platelet antigen-1 to $17 \mathrm{w}$ by polymerase chain reaction sequence-based typing. Vox Sang 2009;97:330-337.

18 Halle L, Bach KH, Martageix C, Bianchi F, Lê T Kim T, Morel-Kopp MC, Soulier J, Tetaria C, Kaplan C: Eleven human platelet systems studied in the Vietnamese and Ma'ohis Polynesian populations. Tissue Antigens 2004;63:34-40. 
19 Macher S, Schallmoser S, Ulrich S, Posch U, Wagner T; Lanzer G: Gene frequencies of human platelet antigens HPA-1, -2, -3 and -5 in Styria and establishment of a panel of HPA-typed platelet donors. Transfus Med Hemother 2004; 31(suppl 1):59 (abstract PO0703).

20 Korinkova P, Suttnar J, Vytiskova J, Stehlikova M: Fetomaternal alloimmune thrombocytopenia - possibilities of diagnosis and exchange transfusion: Ceska Gynekol 1999;64:28-31.

21 Klüter H1, Fehlau K, Panzer S, Kirchner H, Bein G: Rapid typing for human platelet antigen systems-1, -2 , -3 and -5 by PCR amplification with sequence-specific primers: Vox Sang 1996;71:121-125.

22 Mazzucco L, Santi R, Contino L: HPA-1/6 allelomorphism study in juvenile stroke: the possible role of HPA-2b and HPA 5b. 6th European Symposium on Platelet, Granulocyte and Red Cell Immunobiology (Abstract Book) Amsterdam. 2000, p 22.

23 Rozman P, Drabbels J, Schipper RF, Doxiadis I, Stein S, Claas FH: Genotyping for human platelet-specific antigens HPA-1, -2, -3, -4 and -5 in the Slovenian population reveals a slightly increased frequency of HPA-1b and HPA- $2 \mathrm{~b}$ as compared to other European populations. Eur J Immunogenet 1999;26:265-269.

24 Boehlen F, Bulla O, Michel M, Reber G, de Moerloose P: HPA-genotyping and antiplatelet antibodies in female blood donors. Hematol J 2003;4:441-444.

25 Portela CN, Schriefer A, Albuquerque SR, Perdomo RT, Parente AF, Weber SS: The human platelet alloantigen profile in blood donors from Amazonas, Brazil. Transfus Med 2016;26:448-456.

26 Merzoni J, Fagundes IS, Lunardi LW, Lindenau JD, Gi BC, Jobim M, Dias VG, Merzoni L, Sekine L, Onsten TG, Jobim LF: Human platelet antigen genotyping of platelet donors in southern Brazil. Int J Immunogenet 2015;42:329-335.

27 Bianchi JV, Azevedo MR, Jens E, Nukui Y, Chamone DA: Frequency of human platelet antigens in oncohematological patients with thrombocytopenia and the probability to platelet transfusions. Rev Bras Hematol Hemoter 2012;34:202-205.

28 Metsalu T, Vilo J: ClustVis: a web tool for visualizing clustering of multivariate data using principal component analysis and heatmap. Nucleic Acids Res 2015; 43:W566-W570.

29 Saitou N, Nei M: The neighbor-joining method: a new method for reconstructing phylogenetic trees. Mol Biol Evol 1987;4:406-425.

30 Felsenstein J: PHYLIP - Phylogeny Inference Package (Version 3.2). Cladistics 1989;5:164-166.

31 Pena SD, Di Pietro G, Fuchshuber-Moraes M, Genro JP, Hutz MH, Kehdy Fde S, Kohlrausch F, Magno LA, Montenegro RC, Moraes MO, de Moraes ME, de Moraes MR, Ojopi EB, Perini JA, Racciopi C, Ribeiro-DosSantos AK, Rios-Santos F, Romano-Silva MA, Sortica VA, Suarez-Kurtz G: The genomic ancestry of individuals from different geographical regions of Brazil is more uniform than expected. PLoS One 2011;6:e17063.

32 Salzano FM: Molecular variability in Amerindians: widespread but uneven information. An Acad Bras Cienc 2002;74:223-263.

33 Covas DT, Biscaro TA, Nasciutti DC, Guerreiro JF, Santos SEB, Zago MA: Gene frequencies of the HPA-3 and HPA-5 platelet antigen alleles among the Amerindians. Eur J Haematol 2000;65:128-131.

34 da Silva MC, Zuccherato LW, Lucena FC, SoaresSouza GB, Vieira ZM, Pena SD, Martins ML, TarazonaSantos E: Extensive admixture in Brazilian sickle cell patients: implications for the mapping of genetic modifiers. Blood 2011;118:4493-4495.

35 Verran J, Grey D, Bennett J, Lown JA, Erber WN HPA-1, 3, 5 genotyping to establish a typed platelet donor panel. Pathology 2000;32:89-93.

36 Edinur HA, Dunn PP, Lea RA, Chambers GK: Human platelet antigens frequencies in Maori and Polynesian populations. Transfus Med. 2013;23:330-337.

37 Wan Syafawati WU, Norhalifah HK, Zefarina Z, Zafarina Z, Panneerchelvam S, Norazmi MN, Chambers GK, Edinur HA: Allele frequencies of human platelet antigens in Banjar, Bugis, Champa, Jawa and Kelantan Malays in Peninsular Malaysia. Transfus Med 2015;25: 326-332.

8 Castro V, Kroll H, Origa AF, Falconi MA, Marques SB, Marba ST, Passini R Jr, Annichino-Bizzacchi JM, Costa FF, Santoso S, Arruda VR: A prospective study on the prevalence and risk factors for neonatal thrombocytopenia and platelet alloimmunization among 9332 unselected Brazilian newborns. Transfusion 2007; 47:59-66.

39 Berry JE, Murphy CM, Smith GA, Ranasinghe E, Finberg R, Walton J, Brown J, Navarrete C, Metcalfe P, Ouwehand WH. Detection of Gov system antibodies by MAIPA reveals an immunogenicity similar to the HPA-5 alloantigens. Br J Haematol 2000;110:735-742.

40 Ouwehand WH, Smith G, Ranasinghe E. Management of severe alloimmune thrombocytopenia in the newborn. Arch Dis Child Fetal Neonatal Ed 2000;82:F173-175.

41 Ranasinghe E, Walton JD, Hurd CM, Saul L, Smith G, Campbell K, Ouwehand WH: Provision of platelet support for fetuses and neonates affected by severe fetomaternal alloimmune thrombocytopenia. $\mathrm{Br} \mathrm{J}$ Haematol 2001;113:40-42. 